\title{
ПРАВОВОЙ АНАЛИЗ МНОГОСТОРОННЕЙ КОНВЕНЦИИ ПО ВЫПОЛНЕНИЮ МЕР, ОТНОСЯЩИХСЯ К НАЛОГОВЫМ СОГЛАШЕНИЯМ 2016 ГОДА
}

\author{
(c) 2020 Авшалумов Максим Авшалумович \\ аспирант \\ Институт законодательства и сравнительного правоведения \\ при Правительстве Российской Федерации, Россия, Москва \\ E-mail: avshalumos.maks@yandex.ru
}

В настоящей статье осуществляется правовой анализ принятой в 2016 году под эгидой ОЭСР Многосторонней конвенции по выполнению мер, относящихся к налоговым соглашения. Получив краткое наименование «Парижская конвенция», указанный международный договор становится по-настоящему «многосторонним международно-правовым инструментом», который был принят более чем 94 государствами и налоговыми юрисдикциями. Конвенция призвана воплотить в жизнь План действий по борьбе с минимизацией налогообложения и выведением прибыли (МНВП) Организации экономического сотрудничества и развития (ОЭСР) и стран «Большой двадцатки» (G-20). Положения конвенции направлены на решение комплексной проблематики МНВП в соответствии с тремя направлениями: противодействие гибридным схемам снижения налоговой нагрузки (устранение «гибридных несоответствий»), борьба со злоупотреблением положениями налоговых соглашений и противодействие искусственному избежанию статуса постоянного представительства. В заключении отражены основные подходы, которые использует конвенция в соответствии с поставленными перед ней задачами.

Ключевые слова: минимизация налогообложения, выведение прибыли, ОЭСР, гибридные несоответствия, налоговые соглашения, постоянное представительство

\section{Введение}

В 2013 году под эгидой Организации экономического сотрудничества и развития (ОЭСР) в качестве доклада был издан «Проект плана действий по борьбе с минимизацией налогообложения и выведением прибыли»*. Проект направлен на решение проблем, связанных с комплексным явлением «минимизации налогообложения и выведения прибыли» (МНВП)***, которое оказывает вредоносное воздействие на национальную экономику многих государств. МНВП представляет собой два последовательно реализующихся действия: (1) размывание налоговой базы в государстве, где формируется прибыль, и (2) последующее перемещение прибыли в юрисдикции с низким или нулевым налогообложением (офшоры).

В 2015 году на основе Плана действий был разработан «Пакет мер по противодействию МНВП» (the BEPS package)****. Практически одновременно с Пакетом мер была принята Инклюзивная рамочная программа, которая обеспечивает «активное и равноправное участие в данной инициативе развивающихся стран, которым оказывается поддержка в наращивании потенциала»****. Пакет мер состоит из 15 действий, имплементация которых посредством международных и внутригосударственных актов оказывает существенное влияние на противодействие МНВП в государствах-участниках.

\footnotetext{
* Проект плана действий по борьбе с минимизацией налогообложения и выведением прибыли. ОЭСР, 2014 [Электронный ресурс].- https://read.oecd-ilibrary.org/taxation/action-plan-on-base-erosion-and-profit-shiftingrussian-version_9789264207837-ru\#page15 (дата обращения 20.12.2020).

** Аббревиатура МНВП соответствует распространенному англоязычному сокращению BEPS - “Base Erosion and Profit Shifting".

*** Background Brief: Inclusive Framework on BEPS. OECD, January, 2017 [Электронный pecypc].- https://www.oecd. org/tax/beps/background-brief-inclusive-framework-for-beps-implementation.pdf (дата обращения 20.12.2020).

*ж** What is BEPS? Mission and Impact [Электронный ресурс].- https://www.oecd.org/tax/beps/about/\#missionimpact (дата обращения 20.12.2020). В настоящее время в инициативе ОЭСР участвуют 135 государств и налоговых юрисдикций, из которых 66 представлены развивающимися странами.
} 
В рамках пятнадцатой меры Пакета мер была принята Многосторонняя конвенция по выполнению мер, относящихся к налоговым соглашениям от 24 ноября 2016 года (далее - Парижская конвенция, Конвенция)*. Российская Федерация подписала Конвенцию 18 июня 2019 года (вступила в силу 1 октября 2019 года) ${ }^{* *}$. В Российской Федерации действие Конвенции затрагивает 63 соглашения об избежании двойного налогообложения. 30 апреля 2020 года Россия направила Депозитарию ОЭСР уведомление о завершении внутригосударственных процедур, необходимых для начала применения Конвенции в отношении 27 налоговых соглашений ${ }^{* * *}$. В отношении 71 налогового соглашения Россия при ратификации сделала оговорку о начале ее применения только с 1 января 2021 года или заявила о ее неприменении (например, в отношении Швейцарии и Японии). По прогнозу Минфина, все необходимые внутригосударственные процедуры будут завершены до конца 2020 года ${ }^{* * * * * . ~}$

\section{Сфера действия Конвенции}

Сфера действия Конвенции распространяется на все налоговые соглашения, сторонами которых являются как минимум два государства-участника Конвенции. Таким образом, международные обязательства по налоговым соглашениям должны быть приведены и применяться в соответствие с положениями Конвенции. На сегодняшний день Конвенция охватывает более 300 существующих налоговых соглашений, а в прогнозе планируется распространить ее действие еще на 1680 налоговых соглашений

В соответствии с преамбулой Конвенции целями ее принятия является минимизация потерь бюджета в части налога на прибыль организаций, которая является результатом агрессивного международного налогового планирования. Для реализации указанной цели Конвенция устанавливает задачи (1) по предотвращению размывания налоговой базы, (2) выводу прибыли из-под налогообложения, (3) обеспечению налогообложения прибыли по месту ведения основной экономической деятельности, (4) предотвращению злоупотреблений положениями налоговых соглашений, (5) решению проблематики искусственного избежания статуса постоянного представительства. Кроме того, дополнительной задачей Конвенции выступает совершенствование процедуры разрешения споров.

\section{Содержание Конвенции}

Договор состоит из преамбулы и 7 частей, 3 из которых посвящены решению вышеуказанных задач: часть II «Гибридные схемы снижения налоговой нагрузки»; часть III «Злоупотребление положениями соглашений»; часть IV «Избежание статуса постоянного представительства». Кроме того, в Многосторонней конвенции содержатся обширные положения о совершенствовании механизма разрешения споров (часть

\footnotetext{
* Многосторонняя конвенция по выполнению мер, относящихся к налоговым соглашениям, в целях противодействия размыванию налоговой базы и выводу прибыли из-под налогообложения // Собрание законодательства РФ, 09.03.2020, № 10, ст. 1281. По состоянию на декабрь 2020 года Конвенцию подписали 94 государства и еще четыре государства - Алжир, Таиланд, Эсватини и Ливан выразили намерение подписать соглашение в ближайшее время. В 51 государстве и налоговой юрисдикции Конвенция вступила в силу.
}

** Ратификация Конвеции была осуществлена путем издания федерального закона, который в том числе содержит многочисленные оговорки, которые Россия сделала в отношении отдельных статей Парижской конвенции. Подробнее см. Федеральный закон «О ратификации многосторонней конвенции по выполнению мер, относящихся к налоговым соглашениям, в целях противодействия размыванию налоговой базы и выводу прибыли из-под налогообложения» от 1 мая 2019 г. № 79-Ф3 // Собрание законодательства Российской Федерации от 6 мая 2019 г. № 18 ст. 2203.

*** Уведомление размещено на официальной сайте ОЭСР [Электронный pecypc]. - http://www.oecd.org/tax/ treaties/beps-mli-notification-article-35-7-b-russian-federation.pdf (дата обращения 20.12.2020).

**** Информационное сообщение Министерства финансов Российской Федерации о применении многосторонней Конвенции по выполнению мер, относящихся к налоговым соглашениям, в целях противодействия размыванию налоговой базы и выводу прибыли из-под налогообложения от 24 ноября 2016 года [Электронный pecypc]._- https://minfin.gov.ru/ru/document/?id_4=129318-informatsionnoe_soobshchenie_o_primenenii_ mnogostoronnei_konventsii_po_vypolneniyu_mer_otnosyashchikhsya_k_nalogovym_soglasheniyam_v_tselyakh_ protivodeistviya_razmyvaniyu_nal (дата обращения 20.12.2020).

*ж*** OECD/G20 Inclusive Framework on BEPS: Progress Report July 2019-July 2020. OECD, 2020 [Электронный ресурс].- http://www.oecd.org/tax/beps/oecd-g20-inclusive-framework-on-beps-progress-report-july-2019-july-2020. pdf (дата обращения 20.12.2020). 
V) и осуществлению арбитража (часть VI). Конвенция отличается высокой юридической техникой, давая определения используемых в ней понятий в статье 32 «Толкование и применение», а также введением гибких положений о внесении поправок (статья 33), вступлении в силу (статья 34) и применении (статьи 35-36).

Противодействие использованию схем гибридного несоответствия

Под схемами гибридного несоответствия (гибридными схемами снижения налоговой нагрузки) понимаются такие схемы, которые играют на разнице в налогообложении компании или иной налоговой базы (инструмента) двух или более налоговых систем. Согласно Руководству ОЭСР 2012 года* схема может рассматриваться в качестве гибридной, если она включает в себя один или несколько нижеуказанных элементов:

1) организация рассматривается как «прозрачная» (игнорируемая) для целей налогообложения (гибридная организация);

2) организация, которая для целей налогообложения является резидентом двух разных юрисдикций (организация с двойным резидентством);

3) инструменты, которые для целей налогообложения рассматриваются в качестве долга в одной юрисдикции, но как в качестве капитала в другой (гибридные инструменты);

4) соглашения, которые рассматриваются как передача актива для целей налогообложения в одной стране, а в другой не рассматриваются для целей налогообложения (гибридные перево$\partial b l)$.

Указанная логика легла в основу положений Конвенции, которые последовательно посвящены регулированию гибридных организаций: фискально-прозрачных образований (статья 3) и лиц с двойным резидентством (статья 4). Статья 5 посвящена трем методам, которые можно применить в налоговых соглашениях с целью борьбы с гибридными инструментами и переводами.

Различные комбинации гибридных механизмов вписываются, как правило, в одну из следующих схем:

1) «схема двойного вычета» - использование соглашений, в которых вычет, связанный с одним и тем же договорным обязательством, предоставляется в двух разных юрисдикциях;
2) «схема удержания» - механизм, в рамках которого в одной юрисдикции создается вычет (как правило по процентам), который не включается в налогооблагаемый доход в другой юрисдикции;

3) «генераторы иностранных налоговых кредитов» - механизмы, которые при наличии соответствующего налогооблагаемого иностранного дохода генерируют иностранные налоговые кредиты, которые, возможно, в противном случае были бы недоступны.

Руководство 2012 года иллюстрирует одну из типичных комплексных гибридных схем - «схему двойного вычета». Материнская компания, которая является налоговым резидентом страны А косвенно владеет операционной компанией, являющейся резидентом в стране В. Между компаниями А и В существует «гибридная организация», которая рассматривается как «прозрачная» (или «игнорируемая») для целей налогообложения в юрисдикции А и облагаемой налогом в юрисдикции В.При этом, компаниярезидент юрисдикции А обладает всеми или почти всеми долями «гибридной организации», которая контролирует компанию в стране В. «Гибридная организация» берет заем у третьего лица и использует сумму заема для формирования капитала компании в юрисдикции В.

«Гибридная организация» выплачивает проценты по займу и не имеет какого-либо значительного дохода. По этой причине в юрисдикции $\mathrm{B}$ «гибридная организация» может претендовать на налоговый вычет по корпоративному подоходному налогу в размере до $100 \%$. В юрисдикции А «гибридная организация» рассматривается как не подлежащая налогообложению, в результате чего отнесены на расходы компаниирезидента страны А, и также компенсированы путем предоставления вычета. Таким образом, результатом этой схемы является получение двух вычетов по одному и тому же коммерческому обязательству.

Во избежание использования подобных схем Парижская конвенция предусмотрела, что доходы резидента, полученные через «гибридные организации», будут рассматриваться в качестве дохода такого резидента и облагаться корпоративным налогом (пункт 1 статьи 3). Таким образом, они обязаны подлежать налогообложению только в стране В, что исключает налогообложе-

\footnotetext{
* Hybrid Mismatch Arrangements: Tax Policy and Compliance Issues. OECD, 2012 [Электронный pecypc]: http:// www.oecd.org/tax/exchange-of-taxinformation/HYBRIDS_ENG_Final_October2012.pdf (дата обращения 20.12.2020).
} 
ние, а следовательно, получение вычета в стране A.

Для сравнения можно рассмотреть положения Директивы ЕС № 2017/952*, которая направлена на борьбу с гибридными схемами. Согласно общему подходу к гибридному несоответствию, которое приводит к двойному вычету: (а) в вычете должно быть отказано в государстве-члене, которое является юрисдикцией инвестора; и (б) если в вычете не отказано в юрисдикции инвестора, в вычете должно быть отказано в государстве-члене, которое является юрисдикцией плательщика. Таким образом, по общему правилу налоговый вычет должен получаться по месту ведения основной экономической деятельности, что является подходом, аналогичным принятому в рамках Парижской конвенции.

\section{Злоупотребление положениями налого- вых соглашений}

Согласно предусмотренному Планом действий «действию 6» предполагается создание минимальных стандартов для злоупотребления налоговыми соглашениями в целях двойного неналогообложения. Многосторонним инструментом для выполнения действия 6 также становится часть III Парижской конвенции.

Первым минимальным стандартом является включение в налоговые соглашения положения преамбулы о том, что нормы налоговых соглашений не должны создавать возможностей для возникновения ситуации неналогообложения. При этом государство сохраняет право не применять данную формулировку, если в ее налоговых соглашениях уже обеспечено устранение возможности неналогообложения **.

Основным минимальным стандартом пре- дотвращения злоупотребления положениями договоров содержится в пункте 1 статьи 7. Так, если единственной целью создания какой-либо корпоративной структуры или заключения сделки является предоставление налоговой льготы, государство не должно ее предоставлять. Это предполагает необходимость применения предложенного ОЭСР «Теста основной цели» (“Principal purpose test”, PРT)***. Идентичный тест был предусмотрен в результате внесения изменений в 2017 году в пункт 9 статьи 29 Типовой налоговой конвенции ОЭСР 1963 года****.

«Тест основной цели» содержит в себе две составляющие: критерий разумности и критерий основной цели. Их применение определяется в пунктах 10 и 11 комментария к «Тесту основной цели» в Отчете по действию 62015 года ${ }^{* * * * * * . ~ О т-~}$ мечается необходимость проведения объективного анализа целей и задач всех лиц, участвующих в заключении сделки. При этом простое, неподкрепленное доказательствами утверждение лица о том, что сделка не имеет главной целью получение налоговых преимуществ, не является достаточным. Критерий разумности предполагает, что «...все доказательства должны быть взвешены, чтобы определить, является ли разумным вывод о том, что... сделка была предпринята или организована для такой цели»*******.

Договаривающиеся стороны могут принять решение о применении к их налоговым соглашениям «упрощенного положения об ограничении льгот» (simplified limitation of benefits, SLOB), о чем должна быть сделана соответствующая оговорка. Государствами, которые также избрали данный тест, являются Россия, а также Арме-

\footnotetext{
* Council Directive (EU) 2017/952 of 29 May 2017 amending Directive (EU) 2016/1164 as regards hybrid mismatches with third countries // OJ L 144, 7.6.2017, p. 1-11.

** В таком случае Сторона должна сделать оговорку и уведомить об этом Депозитария. Российская Федерация сделала оговорку о неприменении указанного положения о преамбуле в отношении 71 налогового соглашения.

*** Подробнее о применении указанного теста см. Масатбаев А. Упрощенное положение об ограничении льгот (Simplified limitation of benefits) как факультативный условие применения норм конвенций об избежании двойного налогообложения в эпоху Многосторонней налоговой конвенции (MLI) БЭПС ОЭСР [Электронный pecypc]. - https://online.zakon.kz/Document/?doc_id=39619383\#pos=46;-54 (дата обращения 20.12.2020).

***** Model Tax Convention on Income and on Capital: Condensed Version 2017. OECD, 2017 [Электронный ресурс].https://www.oecd.org/ctp/model-tax-convention-on-income-and-on-capital-condensed-version-20745419.htm (дата обращения 21.12.2020).

****** Preventing the Granting of Treaty Benefits in Inappropriate Circumstances, Action 6-2015 Final Report. OECD, 2015 [Электронный ресурс].- https:/www.oecd.org/tax/preventing-the-granting-of-treaty-benefits-ininappropriate-circumstances-action-6-2015-final-report-9789264241695-en.htm (дата обращения 21.12.2020).

******* Обзор PPT (Теста бизнес цели) - положения MLI [Электронный ресурс].- https://bramagroup.com.ua/ blog/obzor-rrt-testa-biznes-czeli-polozheniya-mli (дата обращения 21.12.2020).
} 
ния, Казахстан, Болгария, Греция и Индия.

В целом «это предполагает ограничение круга лиц, которые могут в принципе применять СИДН [соглашения об избежании двойного нлогообложения - прим. автора]»*. Такими лицами становятся «квалифицированные лица», к которым Конвенция относит физических лиц, являющихся резидентами стран-участниц упрощенного положения, а также правительства и иные государственные органы и организации, публичные компании, некоммерческие организации (SLOB 1).

Квалифицированным лицом также может быть признана компания, которая ведет в государстве «активную предпринимательскую деятельность» (SLOB 2). Согласно положениям статьи 7 Конвенции «осуществление активной предпринимательской деятельности» не включает функционирование в качестве холдинговой компании, обеспечение общего надзора или управление группой компаний, предоставление группового финансирования, а также осуществление или управление инвестициями.

Право на льготы также имеют компанииналогоплательщики, более $75 \%$ долей участия которых принадлежат бенефициарам, эквивалентным квалифицированным налогоплательщикам. Под «эквивалентными бенефициарами» Конвенция понимает любое лицо, которое в соответствие с национальным правом имеет право на льготы, которые идентичны или более выгодны, чем предоставляемые налоговыми соглашениями (SLOB 3. Наличие косвенных выгод).

Наконец, льготы будут предоставляться, если налогоплательщик предоставляет налоговому органу доказательства того, что его деятельность не имеет своей главной целью получение льгот на основании упрощенного положения (SLOB 4. Фактическое соответствие).

Искусственное избежание статуса постоянного представительства

Мультинациональные компании разделяют свою деятельность между несколькими юридическими образованиями с тем, чтобы такие образования осуществляли обособленную деятельность в государстве присутствия. Для целей налогообложения создание такого образования приводит к присвоению ему статуса «постоянного представительства». В указанном статусе деятельность постоянного представительства подлежит налогообложению. МНК могут применять различные схемы, которые направлены на искусственное избежание статуса постоянного представительства посредством заключения агентских соглашений (1), за счет использования исключений, предусмотренных для конкретных видов деятельности (2), и разделение контрактов (3).

Согласно положениям статьи 12 Конвенции компания считается имеющей постоянное представительство, если последнее «обычно заключает контракты или обычно играет основную роль, приводящую к заключению контрактов, которые регулярно заключаются без существенных изменений предприятием».

Что касается злоупотребления специальными исключениями, предусмотренными для конкретных видов деятельности, статья 13 Конвенции предусматривает два возможных варианта. Российская Федерация сделала оговорку в пользу варианта, при котором деятельность не охватывается «постоянным представительством» только в том случае, если она специально поименована в налоговом соглашении, при условии, что она носит подготовительный или вспомогательный характер. Такой же вариант регламентации избрали еще 54 юрисдикции.

Положения статьи 14 Конвенции предусматривают механизм, позволяющий предотвратить искусственное избежание статуса постоянного представительства в случае разделения контрактов на несколько частей. Так, если деятельность, осуществляемая на основе таких контрактов, длится в совокупности более, чем 30 дней, то она образует постоянное представительство. Положения подпункта «а» пункта 2 статьи 14 Конвенции позволяет государствамучастницам не применять статью к налоговым соглашениям. Всего 34 юрисдикции, включая Россию, применяют положения Конвенции на случай разделения контрактов без оговорок.

\section{Заключение}

Явление МНВП не является новым объектом международного налогового права. Тем не менее, возникают все новые и новые действия, которые позволяют отдельным налогоплательщикам извлекать преимущества в результате злоупотребления возможностями и льготами, предоставленными налоговыми соглашениями и внутригосударственным правом.

\footnotetext{
* MLI быть: новый этап в применении СИДН [Электронный ресурс].- https://home.kpmg/ru/ru/home/ insights/2019/05/mli-russia-news.html (дата обращения 29.12.2020).
} 
В 2016 году была принята Парижская конвенция, целью которой является внесение поправок в существующие налоговые соглашения между 135 государствами и налоговыми юрисдикциями, которые участвуют в Инклюзивной рамочной программе МНВП ОЭСР. Конвенция предоставляет участникам гибкие механизмы, благодаря которым возможно адаптировать сроки начала ее применения под возможности и состояние права отдельного государства, избрать для себя подходящие правовые инструменты, а также прибегнуть к многочисленным оговоркам, предусмотренным в тексте Конвенции. Российская Федерация ратифицировала и уже применяет положения указанной Конвенции.

Конвенция ставит перед собой три важнейших задачи, которые позволяют достичь цель по противодействию МНВП: борьба с гибридными схемами снижения налоговой нагрузки, противодействие злоупотреблению положениями налоговых соглашений и борьба с искусственным избежанием статуса постоянного представительства.

Борьба с гибридными схемами несоответствия осуществляется в отношении гибридных организаций, организаций с двойным резидентством, гибридных инструментов и гибридных переводов. Различные комбинации гибридных механизмов используются в рамках схем двой- ного вычета, удержания и генерации иностранных налоговых кредитов. Основным правилом конвенции становится правило, в соответствии с которым налоговый вычет и удержание осуществляются по месту получения дохода, который облагается корпоративным доходом, а не в юрисдикции инвестора.

Злоупотребление положениями налоговых соглашений, которое заключается в попытке создания ситуации двойного неналогообложения, решается путем указания на борьбу с данным явлением в преамбуле налоговых соглашений. Основными инструментами борьбы со злоупотреблением остаются «тест основной цели» и «тест положения об ограничении льгот», между которыми государства-участники Конвенции могут осуществлять выбор.

Искусственное избежание статуса постоянного представительства предотвращается посредством определения того, какую роль юридическое образование играет в рамках заключения коммерческих контрактов, а также выяснением того, осуществляет ли указанное образование только подготовительный или вспомогательный характер при заключении коммерческих сделок. Отдельная статья Конвенции посвящена предотвращению злоупотреблений, связанных с искусственным разделением контрактов на несколько частей.

\section{Библиографический список}

1. Информационное сообщение Министерства финансов Российской Федерации о применении многосторонней Конвенции по выполнению мер, относящихся к налоговым соглашениям, в целях противодействия размыванию налоговой базы и выводу прибыли из-под налогообложения от 24 ноября 2016 года [Электронный ресурс].- https://minfin.gov.ru/ru/document/?id_4=129318-informatsionnoe_soobshchenie_o_primenenii_ mnogostoronnei_konventsii_po_vypolneniyu_mer_otnosyashchikhsya_k_nalogovym_soglasheniyam_v_tselyakh_ protivodeistviya_razmyvaniyu_nal (дата обращения 20.12.2020).

2. MLI быть: новый этап в применении СИДН [Электронный pecypc].- https://home.kpmg/ru/ru/home/ insights/2019/05/mli-russia-news.html

3. Масатбаев А. Упрощенное положение об ограничении льгот (Simplified limitation of benefits) как факультативный условие применения норм конвенций об избежании двойного налогообложения в эпоху Многосторонней налоговой конвенции (MLI) БЭПС ОЭСР [Электронный ресурс].- https://online.zakon.kz/ Document/?doc_id=39619383\#pos=46;-54

4. Многосторонняя конвенция по выполнению мер, относящихся к налоговым соглашениям, в целях противодействия размыванию налоговой базы и выводу прибыли из-под налогообложения // Собрание законодательства РФ, 09.03.2020, № 10, ст. 1281

5. Обзор PPT (Теста бизнес цели) - положения MLI [Электронный ресурс]. - https://bramagroup.com.ua/blog/ obzor-rrt-testa-biznes-czeli-polozheniya-mli

6. Проект плана действий по борьбе с минимизацией налогообложения и выведением прибыли. ОЭСР, 2014 [Электронный ресурс].- https://read.oecd-ilibrary.org/taxation/action-plan-on-base-erosion-and-profitshifting-russian-version_9789264207837-ru\#page15

7. Уведомление размещено на официальной сайте ОЭСР [Электронный pecypc].- http://www.oecd.org/tax/ treaties/beps-mli-notification-article-35-7-b-russian-federation.pdf 
8. Федеральный закон «О ратификации многосторонней конвенции по выполнению мер, относящихся к налоговым соглашениям, в целях противодействия размыванию налоговой базы и выводу прибыли из-под налогообложения» от 1 мая 2019 г. № 79-Ф3 // Собрание законодательства Российской Федерации от 6 мая 2019 г. № 18 ст. 2203

9. Background Brief: Inclusive Framework on BEPS. OECD, January, 2017 [Электронный pecypc].- https://www. oecd.org/tax/beps/background-brief-inclusive-framework-for-beps-implementation.pdf

10. Council Directive (EU) 2017/952 of 29 May 2017 amending Directive (EU) 2016/1164 as regards hybrid mismatches with third countries // OJ L 144, 7.6.2017, p. 1-11.

11. Hybrid Mismatch Arrangements: Tax Policy and Compliance Issues. OECD, 2012 [Электронный ресурс]: http:// www.oecd.org/tax/exchange-of-taxinformation/HYBRIDS_ENG_Final_October2012.pdf

12. Model Tax Convention on Income and on Capital: Condensed Version 2017. OECD, 2017 [Электронный ресурс].https://www.oecd.org/ctp/model-tax-convention-on-income-and-on-capital-condensed-version-20745419.htm

13. OECD/G20 Inclusive Framework on BEPS:Progress Report July 2019-July 2020. OECD, 2020 [Электронный ресурс].http://www.oecd.org/tax/beps/oecd-g20-inclusive-framework-on-beps-progress-report-july-2019-july-2020.pdf

14. Preventing the Granting of Treaty Benefits in Inappropriate Circumstances, Action 6-2015 Final Report. OECD, 2015 [Электронный ресурс].- https://www.oecd.org/tax/preventing-the-granting-of-treaty-benefits-ininappropriate-circumstances-action-6-2015-final-report-9789264241695-en.htm

15. What is BEPS? Mission and Impact [Электронный ресурс].- https://www.oecd.org/tax/beps/about/\#missionimpact 